\title{
Determinan Audit Report Lag Dengan Auditor Spesialisasi Industri Sebagai Variabel Moderating Pada Perusahaan Go Public Sektor Pertambangan Terdaftar Di Bei Periode 2014-2018
}

\author{
Aulia Rahman Harahap ${ }^{1 *}, \operatorname{Irfan}^{2}$, Mayasari $^{2}$, Nancy Mayriski Siregar ${ }^{3}$ \\ ${ }^{1}$ Satuan Audit Internal, Universitas Sumatera Utara \\ ${ }^{2}$ Magister Akuntansi, Universitas Muhammadiyah Sumatera Utara \\ ${ }^{3}$ Fakultas Sosial Sains, Universitas Pembangunan Pancabudi Medan \\ E-mail: aulia.harahap@usu.ac.id
}

\begin{abstract}
The purpose of the study was to examine the effect of audit committee size, auditor tenure and $K A P$ size on audit report lag with industry specialization auditors as moderating variables in publicly listed mining sector companies on the IDX. This research is a quantitative research using secondary data that is accessed from the website of the mining sector company. This study uses the criteria to determine the research sample, amounting to 31 companies. The method of analysis used logistic regression and residual test which was processed with SPSS. The results of the study: 1) the size of the audit committee has no effect on audit report lag; 2) audit tenure has no effect on audit report lag; 3) KAP size has an effect on audit report lag; 4) all independent variables simultaneously affect the audit report lag; 5) the moderating variable cannot moderate the effect of the independent variable on audit report lag.
\end{abstract}

Keywords: audit committee size, auditor tenure, KAP size, auditor specialization industry, audit report lag.

\begin{abstract}
Abstrak
Tujuan penelitian untuk menguji pengaruh ukuran komite audit, auditor tenure dan ukuran KAP terhadap audit report lag dengan auditor spesialisasi industri sebagai variabel moderating pada perusahaan sektor pertambangan go public terdaftar di BEI. Penelitian ini merupakan penelitian kuantitatif dengan menggunakan data sekunder yang diakses dari website perusahaan sektor pertambangan. Penelitian ini menggunakan kriteria untuk menentukan sampel penelitian yang berjumlah 31 perusahaan. Metode analisis menggunakan regresi logistik dan uji residual yang diolah dengan SPSS. Hasil penelitian: 1) ukuran komite audit tidak berpengaruh terhadap audit report lag; 2) audit tenure berpengaruh tidak berpengaruh terhadap audit report lag; 3) ukuran KAP berpengaruh terhadap audit report lag; 4) seluruh variabel bebas secara simultan berpengaruh terhadap audit report lag; 5) variabel moderasi tidak dapat memoderasi pengaruh variabel bebas terhadap audit report lag.
\end{abstract}

Kata Kunci : ukuran komite audit, auditor tenure, ukuran KAP, auditor spesialisasi industri, audit report lag.

doi: https://doi.org/10.51544/jma.v6i2.1996

(C) 2021 Jurnal Mutiara Akuntansi. This is an open access article under the CC BY-SA licenseWebsite: http://e-journal.sari-mutiara.ac.id/index.php/JMA/ 


\section{PENDAHULUAN}

Keputusan ekonomi yang diambil oleh para pengambil keputusan sudah tentu memerlukan informasi yang relevan dan dapat diandalkan. Informasi tersebut tersaji pada laporan keuangan entitas, para pihak yang berkepentingan atas informasi akuntansi yang relevan dan andal antara lain adalah manajemen, investor, karyawan, kreditor, pemerintah, pelangan, dan masyarakat berdasarkan kepentingan yang berbeda-beda. Informasi akuntansi yang ada pada laporan keuangan merupakan informasi penting karena informasi akuntansi tersebut mencerminkan kinerja keuangan, perubahan ekuitas, arus kas dan aktiva yang dimiliki entitas. Laporan keuangan yang berkualitas dan bermanfaat memiliki kriteria relevan, andal, dapat dibandingkan, dan dapat dipahami (Ikatan Akuntan Indonesia, 2018).

Informasi akuntansi yang berkualitas atau laporan keuangan entitas yang berkualitas adalah informasi atau laporan keuangan yang relevan dan andal yang telah diperiksa atau di audit oleh Kantor Akuntan Publik (KAP) (Alkhatib \& Marji, 2012). Audit atas laporan keuangan merupakan serangkaian prosedur yang sistematis dan kritis atas informasi akuntansi pada laporan keuangan entitas yang diteliti hingga bukti pendukung atau dasar pencatatan dengan tujuan menilai kewajaran laporan keuangan entitas (Arens et al,2017) maka dapat diintisarikan bahwa laporan keuangan entitas yang berkualitas dan informasi akuntansi didalamnya diyakini relevan dan andal adalah laporan keuangan entitas yang telah di audit oleh KAP sehingga kewajaran laporan keuangan entitas telah di jamin oleh KAP. Jika laporan keuangan entitas belum di audit oleh KAP maka belum ada pihak berkompeten yang menyatakan kewajaran laporan keuangan entitas tersebut sehingga informasi akuntansi didalamnya belum dapat diyakini mengenai relevansi dan keandalannya.

Output dari audit adalah opini auditor terhadap laporan keuangan entitas yang nilai kewajaran atas pencatatan, pengukuran, pengakuan dan penyajian atas informasi akuntansi yang ada di laporan keuangan entitas. Opini audit dari KAP mengenai kewajaran laporan keuangan entitas berupa opini tanpa modifikasi dan opini dengan modifikasi dimana opini dengan modifikasi berarti ada terdapat beberapa ketidak wajaran atas informasi akuntansi pada laporan keuangan entitas baik itu bernilai signifikan ataupun tidak signifikan ( Agoes, 2019)

Ketepatan penyampaian laporan keuangan entitas kepada publik akan sangat berdampak signidikan terhadap relevansi atau value dari laporan keuangan itu sendiri. Dimana laporan keuangan akan kehilangan relevansinya jika terlambat disajikan kepada public. Laporan keuangan merupakan indikator atau barometer yang dapat dilihat oleh public atas kinerja manajemen entitas pada satu periode tertentu. Penyelesaian laporan keuangan entitas dan lamanya penyelesaian audit atas laporan keuangan (audit report lag) adalah indikator keberhasilan entitas dalam meningkatkan kualitasnya (Wariyanti \& Suryono, 2017)

Fenomena yang ada mengenai audit report lag periode 2014-2018 masih terjadi dan dialami oleh perusahaan-perusahaan go public yang terdaftar pada Bursa Efek Indonesia (BEI). Pada tahun 2018 terdapat 10 entitas yang mengalami audit report lag, 10 entitas pada tahun 2017, 17 entitas pada tahun 2016, 18 entitas pada tahun 2015 dan 52 entitas pada tahun 2014.

Audit report lag disebabkan oleh kemampuan dan pengetahuan auditor dalam menyelesaikan pekerjaanya/auditnya dimana auditor yang memiliki kompetensi dan pengalaman yang memadai akan dapat menyelesaikan auditnya tepat waktu.

Ukuran komite audit berdasarkan Peraturan OJK Nomor 55/POJK.04/2015 tentang pelaksanaan kerja komite audit dijelaskan bahwa salah satu tugas dan fungsi komite audit minimal berjumlah tiga orang. Maka ukuran komite audit adalah jumlah komite audit yang dimiliki perusahaan; 
1. Auditor tenure adalah masa perikat/kerjasama yang terjalin antara akuntan publik tertentu dengan perusahaan tertentu. Auditor tenure dapat dinilai dengan menghitung jumlah perikat yang terjadi antara auditor dengan perusahaan;

2. Ukuran KAP dapat dinilai dengan melihat affiliasi KAP tersebut dimana jika KAP beraffiliasi dengan salah satu KAP :

1. KPMG Internasional Coorperative berafiliasi dengan Siddharta Widjaja \& Rekan;

2. Deloite Touch Tehmatsu Limited berafiliasi dengan Imelda \& Rekan;

3. Ernest \& Young Global Limited berafiliasi dengan Purwantono, Sungkoro \& Surja;

4. Pricewaterhouse Coopers Internasioanl Limited berafiliasi dengan Tanudiredja, Wibisana, Rintis dan Rekan.

dikategorikan sebagai KAP Big four sementara KAP yang tidak beraffiliasi dengan KAP tersebut diatas dikatagorikan sebagai KAP Non Big four;

4. Auditor spesialisasi industri merupakan auditor yang memiliki pengetahuan yang memadai pada industri tertentu. Untuk menilai auditor spesialisasi industri dengan melihat berapaka kali auditor tersebut mengaudit pada satu periode atas suatu industri dalm penelitian ini jika telah mengaudit tiga perusahaan pada satu periode audit maka tergolong auditor spesialisasi industri.

\section{Kerangka Konseptual}

Kerangka konseptual atau kerangka pemikiran merupakan konstruksi berpikir yang digunakan oleh peneliti yang bersifat logis dengan menggunakan argumen yang memadai. Dalam penelitian ini, peneliti mencoba mengkaji hubungan reputasi KAp, auditor tenure dan opini audit terhadap audit report lag. Adapun kerangka konseptual yang dapat peneliti gambarkan adalah sebagai berikut:

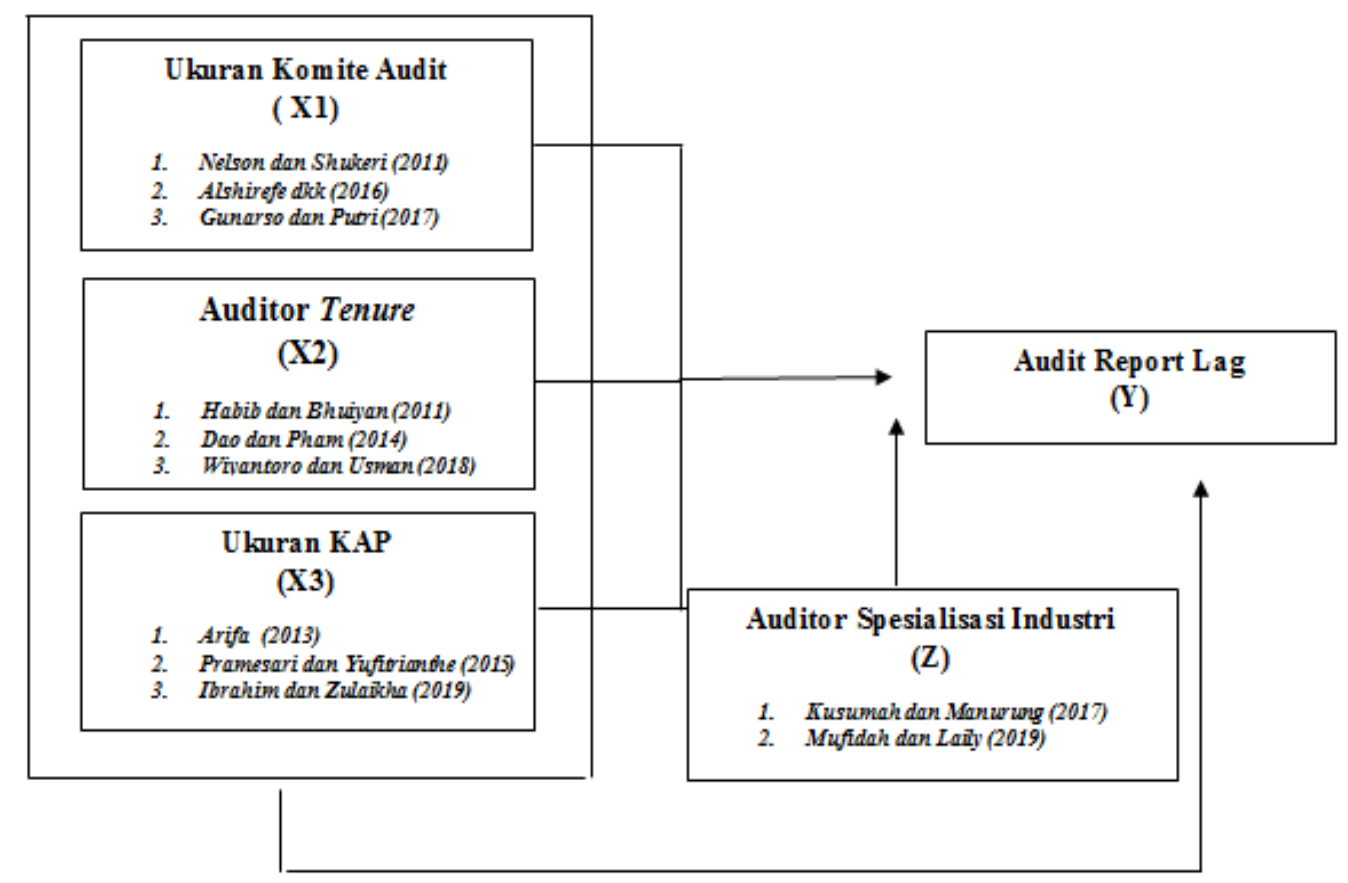




\section{Hipotesis}

Berdasarkan kerangka konseptual yang telah diuraikan, maka dikemukakan hipotesis sebagai berikut:

1. Ada pengaruh ukuran komite audit terhadap audit report lag ?

2. Ada pengaruh auditor tenure terhadap audit report lag ?

3. Ada pengaruh ukuran KAP terhadap audit report lag?

4. Ada pengaruh ukuran komite audit, audit tenure dan ukuran KAP secara simultan terhadap audit report lag?

5. Auditor spesialisasi industri dapat memoderasi pengaruh ukuran komite audit terhadap audit report lag?

6. Auditor spesialisasi industri dapat memoderasi pengaruh auditor tenure terhadap audit report lag?

7. Auditor spesialisasi industri dapat memoderasi pengaruh ukuran KAP terhadap audit report lag?

\section{METODE PENELITIAN}

\section{Jenis Penelitian}

Penelitian ini menggunakan pendekatan asosiatif dimana menurut Juliandi dan Irfan (2013) penelitian yang menggunakan pendekatan asosiatif adalah penelitian atau research yang dilakukan untuk mendapatkan bukti empiris mengenai keterkaitan, pengaruh dan hubungan antara variabel dependen terhadap variabel independen yang diteliti. Penelitian ini berjenis penelitian kuantitatif dengan menggunakan data sekunder yang didapat dari laporan tahunan perusahaan go public sektor pertambangan yang terdaftar di BEI.

\section{Populasi dan Sampel}

Populasi pada penelitian ini adalah perusahaan pertambangan dengan jumlah 50 perusahaan adapun perusahaan pertambangan yang dijadikan sample dalam penelitian ini sebanyak 31 perusahaan yang ditetapkan dengan menggunakan kriteria sebagai berikut:

1. Sampel penelitian ialah perusahaan sektor pertambangan yang terdaftar di BEI pada periode 2014-2018;

2. Sampel penelitian ialah perusahaan sektor pertambangan yang mengunduh/mengupload laporan tahunan periode 2014-2018 pada website/laman pribadi perusahaan;

3. Sampel penelitian ialah perusahaan sektor pertambangan yang laporan keuangannya di audit oleh Kantor Akuntan Publik (KAP);

4. Sampel penelitian ialah perusahaan sektor pertambangan yang laporan keuangannya di audit oleh Kantor Akuntan Publik (KAP);

\section{Defenisi Variabel}

Tujuan definisi operasional variabel ialah menunjukkan bagaimana suatu variabel dapat di ukur dan di uji yang diharapkan dapat berguna untuk menganalisis pengaruh variabel-variabel yang digunakan pada penelitian ini. Dalam penelitian ini terdapat tiga variabel dependen, satu variabel independen dan satu variabel moderating adapun variabel yang digunakan dalam pada penelitian ini ialah:

1. Audit report lag (Y), Ketaatan penyampaian laporan keuangan audited yang diukur menggunakan dummy dimana $1=$ untuk perusahaan yang menyampaikan laporan keuangan tepat waktu (paling lambat 120 hari setelah tanggal tutup buku) dan 0 = untuk perusahaan yang terlambat menyampaikan laporan keuangan Wendy dkk (2019), Hersugondo dan Kartika (2013);

2. Ukuran komite audit $\left(\mathrm{X}_{1}\right)$, Jumlah komite audit yang dimiliki perusahaan yang diukur dengan mengkumulatifkan jumlah member komite audit Hani dan Hafsah (2017), Alshrifel (2016); 
3. Auditor tenure $\left(\mathrm{X}_{2}\right)$, Jumlah tahun perikatan yang diukur dengan mengkumulatifkan jumlah perikatan KAP dengan perusahaan Michael dan Rohman (2017), Nurfita dan Setyorini (2017);

4. Ukuran KAP $\left(\mathrm{X}_{3}\right)$, KAP yang beraffiliasi dengan KAP asing audited yang diukur menggunakan dummy dimana $1=$ untuk KAP yang beraffiliasi dengan Big four dan $\quad 0=$ untuk KAP yang tidak beraffiliasi dengan Big four Astuty (2016), Sari dkk (2014);

5. Auditor spesalisasi industri (Z), Pemahaman KAP/auditor terhadap industri klien yang dihitung dengan rumus $10 \%$ dari sampel penelitian audited yang diukur menggunakan dummy dimana $1=$ untuk auditor spesialisasi industri dan $0=$ untuk non-auditor spesialisasi industry Setiawan dan Fitriany, (2011), Siregar (2009)

\section{Teknik Pengumpulan Data}

Teknik pengumpulan data yang digunakan peneliti di dalam pengumpulkan data-data yang diperlukan adalah metode dokumentasi terhadap data sekunder yang berbentuk laporan tahunan dan laporan keuangan audited periode 2014 - 2018 yang dapat diakses pada laman perusahaan go public sektor pertambangan.

\section{Teknik Analisis Data}

Penelitian ini menggunakan analisis data regresi logistik ini dikarenakan variabel dependen yang akan diuji Audit report lag (Y) adalah variabel berskala nominal yang diwakili angka 1 jika terjadi audit report lag dan angka 0 jika tidak terjadi audit report lag. Menurut Ghozali (2013) regresi logistik dipakai untuk menguji probabilitas terjadinya variabel dependen yang dapat diprediksi dengan variabel independennya. Asumsi normalitas data dapat diacuhkan pada model penelitian yang menngunakan analisis regresi logistik.

\section{Hasil dan Pembahasan}

\section{Statistik Deskriptif}

Analisis statistik deskriptif dilakukan agar dapat menyeleksi data, sehingga data yang dianalisis terdistribusi dengan normal. Dalam penelitian ini variable dependen ialah audit report lag (Y), variable moderating ialah auditor spesialisasi industry (Z) dan variable independen ialah ukuran komite audit $\left(\mathrm{X}_{1}\right)$, auditor tenure $\left(\mathrm{X}_{2}\right)$, dan ukuran $\operatorname{KAP}\left(\mathrm{X}_{3}\right)$. Berdasarkan analisis statistik deskriptif didapatkan hasil sebagai berikut:

\begin{tabular}{|l|c|c|c|c|c|}
\hline & $\mathrm{N}$ & Minimum & Maximum & Mean & $\begin{array}{c}\text { Std. } \\
\text { Deviation }\end{array}$ \\
\hline Audit Report Lag & 155 & 0 & 1 & .87 & .336 \\
Ukuran Komite Audit & 155 & 2 & 4 & 3.14 & .412 \\
Auditor Tenure & 155 & 1 & 3 & 1.53 & .687 \\
Ukuran KAP & 155 & 0 & 1 & .53 & .501 \\
Valid N (listwise) & 155 & & & & \\
\hline
\end{tabular}

\section{Uji Hipotesis}

\section{Uji Wald (parsial)}

Pada regresi logistik, uji signifikansi parsial variabel-variabel independen terhadap variabel dependen disimpulkan melalui hasil uji Wald. Dalam uji Wald, statistik yang diuji adalah statistik Wald (Wald statistic). Nilai statistik dari uji Wald berdistribusi Chi-Square. Pengambilan keputusan terhadap hipotesis dapat dilakukan dengan menggunakan pendekatan nilai probabilitas uji wald dengan kriteria sebagai berikut: 
a. Bila Chi-Square hitung < Chi-Square tabel dan nilai sig. > 0.05, artinya bahwa secara parsial variabel independen tidak berpengaruh terhadap variabel dependen;

b. Bila Chi-Square hitung > Chi-Square tabel dan nilai sig. $<0.05$, artinya bahwa secara parsial variabel independen berpengaruh terhadap variabel dependen.

Dengan hipotesis sebagai berikut:

a. $\mathrm{H}_{0}=$ artinya variabel independent tidak berpengaruh terhadap variabel dependen;

b. $\mathrm{H}_{\mathrm{a}}=$ artinya variabel independent berpengaruh terhadap variabel dependen. Hasil dari uji Wald sebagai berikut:

\begin{tabular}{|ll|c|c|c|c|c|c|}
\hline & & B & S.E. & Wald & df & Sig. & Exp(B) \\
\hline \multirow{4}{*}{ Step 1 $^{\text {a }}$} & X1 & -.231 & .518 & .199 & 1 & .655 & .794 \\
& X2 & .116 & .358 & .105 & 1 & .746 & 1.123 \\
& X3(1) & -1.845 & .625 & 8.708 & 1 & .003 & .158 \\
& Constant & 3.579 & 1.868 & 3.671 & 1 & .055 & 35.829 \\
\hline
\end{tabular}

a. Variable(s) entered on step 1: X1, X2, X3.

Pengujian hipotesis dilakukan dengan cara membandingkan antara tingkat signifikansi (Sig.) dengan tingkat $(\alpha)$ 5\%. Dari pengujian menggunakan regresi logistik di atas maka diperoleh persamaan regresi logistik sebagai berikut:

$$
\mathrm{LN} \frac{P(A R L)}{1-P(A R L)}=3.579-0.231 \mathrm{X}_{1}+0.116 \mathrm{X}_{2}-1.845 \mathrm{X}_{3}
$$

\section{Dimana :}

$\mathrm{P} \quad=$ probabilitas audit report lag

$\mathrm{b}_{0} \quad=$ konstanta

$\mathrm{b}_{1}-\mathrm{b}_{3} \quad=$ koefisien regresi varibel independen

$\mathrm{X}_{1} \quad=$ koefisien regresi ukuran komite audit

$\mathrm{X}_{2} \quad=$ koefisien regresi auditor tenure

$\mathrm{X}_{3} \quad=$ koefisien regresi ukuran KAP

Dapat dinterpretasikan hasil uji Wald/parsial variabel independen terhadap variabel dependen sebagai berikut:

1. Pengaruh Ukuran Komite Audit Terhadap Audit Report Lag

Ukuran komite audit berpengaruh negatif terhadap audit report lag dengan chi square hitung 0.199 < chi square tabel 3.8145 dengan nilai probalilitas (Sig.) $0.655>$ dari 0.05 , maka ukuran komite audit tidak berpengaruh terhadap audit report lag. Dengan demikian hipotesis $\mathrm{H}_{0}$ diterima dan hipotesis $\mathrm{H}_{a}$ ditolak.

2. Pengaruh Auditor Tenure Terhadap Audit Report Lag

Auditor tenure berpengaruh positif terhadap audit report lag dengan chi square hitung $0.105<$ chi square tabel 3.8145 dengan nilai dengan nilai probalilitas (Sig.) 0.746 yang > dari 0.05 , maka auditor tenure tidak berpengaruh terhadap audit report lag. Dengan demikian hipotesis $\mathrm{H}_{0}$ diterima dan hipotesis $\mathrm{H}_{\mathrm{a}}$ ditolak.

3. Pengaruh Ukuran KAP Terhadap Audit Report Lag

Ukuran KAP berpengaruh negatif terhadap audit report lag dengan chi square hitung $8.708>$ chi square tabel 3.8145 dengan nilai probalilitas (Sig.) 0.003 $<$ dari 0.05, maka ukuran KAP berpengaruh terhadap audit report lag. Dengan demikian hipotesis $\mathrm{H}_{0}$ ditolak dan hipotesis $\mathrm{H}_{\mathrm{a}}$ diterima. 


\section{Uji Omnibus (Simultan)}

Pada regresi logistik, uji signifikansi simultan variabel-variabel independen terhadap variabel dependen disimpulkan melalui hasil uji Omnibus. Dalam uji Omnibus, pengambilan keputusan terhadap hipotesis dapat dilakukan dengan cara membandingkan antara tingkat signifikansi (Sig.) dengan tingkat ( $\alpha$ ) 5\% dengan kriteria sebagai berikut:

a. Bila Chi-Square hitung < Chi-Square tabel dan nilai sig. > 0.05, artinya bahwa secara simultan variabel independen tidak berpengaruh terhadap variabel dependen;

b. Bila Chi-Square hitung > Chi-Square tabel dan nilai sig. $<0.05$, artinya bahwa secara simultan variabel independen berpengaruh terhadap variabel dependen.

Dengan hipotesis sebagai berikut:

a. $\mathrm{H}_{0}=$ artinya variabel independen secara simultan tidak berpengaruh terhadap variabel dependen;

b. $\mathrm{H}_{\mathrm{a}}=$ artinya variabel independen secara simultan berpengaruh terhadap variabel dependen.

Hasil dari uji Omnibus sebagai berikut:

\begin{tabular}{|ll|c|c|c|}
\hline & & Chi-square & df & Sig. \\
\hline \multirow{3}{*}{ Step 1 } & Step & 11.189 & 3 & .011 \\
& Block & 11.189 & 3 & .011 \\
& Model & 11.189 & 3 & .011 \\
\hline
\end{tabular}

Diketahui bahwa chi square hitung $11.189>$ dari chi square tabel 7.8147 nilai probabilitas (Sig.) uji signifkansi variabel independen secara simultan terhadap variabel dependen sebesar $0.011<0.05$. Maka hipotesis $\mathrm{H}_{0}$ ditolak dan hipotesis $\mathrm{H}_{\mathrm{a}}$ diterima dengan demikian dapat disimpulkan bahwa ukuran komite audit $\left(\mathrm{X}_{1}\right)$, auditor tenure $\left(\mathrm{X}_{2}\right)$ dan ukuran $\mathrm{KAP}\left(\mathrm{X}_{3}\right)$ secara simultan mempengaruhi audit report lag (Y).

\section{KESIMPULAN}

Berdasarkan hasil pembahasan yang telah dilakukan dalam penelitian ini, maka kesimpulan yang dapat peneliti sampaikan sebagai berikut:

1. Ukuran komite audit tidak berpengaruh terhadap audit report lag;

2. Auditor tenure tidak berpengaruh terhadap audit report lag;

3. Ukuran KAP berpengaruh terhadap audit report lag;

4. Ukuran komite audit, auditor tenure dan ukuran KAP secara simultan berpengaruh terhadap audit report lag;

5. Auditor spesialisasi industri tidak dapat memoderasi pengaruh ukuran komite audit terhadap audit report lag;

6. Auditor spesialisasi industri tidak dapat memoderasi pengaruh auditor tenure terhadap audit report lag;

7. Auditor spesialisasi industri tidak dapat memoderasi pengaruh ukuran KAP terhadap audit report lag;

\section{SARAN}

Berdasarkan hasil penelitian yang telah diuraikan diatas, maka peneliti menyarankan kepada perusahaan go public sektor pertambangan yang mengalami keterlambatan dalam penyampaian laporan tahunan agar :

1. Pada masa yang akan datang meningkatkan jumlah komite audit, hal ini disebabkan jumlah komite audit dengan ukuran dua sampai dengan empat orang belum mampu memberikan kontribusi pada penurunan audit report lag jika dibiarkan ini akan berdampak pada reputasi perusahaan dikalangan para investor 
dan pengguna laporan keungan yang bisa berakibat pada hilangnya niat investor untuk berinveatasi pada perusahaan;

2. Agar tidak terpaku atau terus menggunakan akuntan publik tertentu untuk mengaudit laporan keuangan perusahaan, hal ini dikarenakan tidak ada pengaruh yang signifikan terhadap audit report lag dengan menggunakan akuntan publik yang sama berulang-ulang. Dengan penggunaan akuntan publik yang sama berulang-ulang dan masih terjadi keterlambatan penyampaian laporan tahunan akan membuat prasangka negatif investor dan pengguna laporan keuangan kepada manajemen perusahaan. Dimana akan ada pemikiran bahwa keterlambatan penyampaian laporan tahunan disebabkan adanya kesepakatan antara manajemen perusahaan dengan akuntan publik (akuntan publik tidak independen) untuk tidak menyajikan temuan salah saji yang material pada laporan keuangan perusahaan;

3. Untuk menggunakan KAP big four dalam mengaudit laporan keuangan perusahaan, hal ini disebabkan dengan mengunakan KAP big four dapat menurunkan audit report lag. KAP big four memiliki kualitas audit dan auditor yang memadai sehingga akan berdampak signifikan terhadap audit report lag. Selain akan terhindar dari pembayaran denda keterlambatan penyampaian laporan tahunan perusahaan, ini akan berdampak pada baiknya reputasi manajemen perusahaan dipandangan investor dan pengguna laporan keuangan terutama pada perspektif akuntabilitas perusahaan;

4. Tidak perlu menggunakan auditor spesialisasi industri karena auditor spesialisasi industri tidak dapat memoderasi pengaruh ukuran komite audit, auditor tenure dan ukuran KAP terhadap audit report lag selain itu auditor spesialisasi industri untuk mendapatkan keyakinan terhadap kewajaran nilai-nilai yang tercantum pada akun-akun laporan keuangan akan membandingkan dengan industri sejenis ini tentu memerlukan waktu ekstra dalam menyelesaikan auditnya. Hal lain yang perlu dipertimbangkan dalam penggunaan auditor spesialisasi industri adalah banyaknya perusahaan pada industri sejenis yang menggunakan jasa auditor tersebut yang akan berdampak pada kurang optimalnya kinerja auditor tersebut pada penyelesaian audit.

\section{DAFTAR PUSTAKA}

Alshrife, F.M, Iman Subekti, And Yeney Widya. 2016. "The International Journal of Accounting And Business Society 92." 24(2): 92-112.

Arens, Alvin. A, Randal . J Elder, And Mark. S Beasly. 2015. Auditing \& Jasa Asurance Jilid I. Jakarta: Erlangga.

Alkhatib, A. and Harasheh, M. (2012) Financial Performance of Palestinian Commercial Banks. International Journal of Business and Social Science, 3, 175-184.

Agoes, Soekrisno. 2019. Auditing Petunjuk Praktis Pemeriksaan Akuntan oleh Akuntan Publik. Jilid 1, Edisi 4. Jakarta

Astuty, Widia. 2016. "Profitabilitas, Ukuran Perusahaan, Reputasi Kantor Akuntan Publik, Audit Report Lag Terhadap Ketepatan Waktu Pelaporan.” Proceeding Forum Manajemen

Ghozali, Iman. 2015. Statistik Non Parametrik. Semarang: Badan Penerbit Universitas Diponegoro. . 2017. Model Struktural. Semarang: Badan Penerbit Universitas Diponegoro.

Hani, Syafrida, And Hafsyah Hafsyah. 2017. "Good Corporate Governance Mechanisms In Measuring Quality Of Financial Statements And Transfer Investor Levels." International Journal Of Recent Scientific Research 8(5): 17092-96.

Hersugondo, And Andi Kartika. 2013. "Prediksi Probabilitas Audit Delay Dan Faktor Determinannya.” Jurnal Ekonomi Manajemen Akuntansi 20(35): 1-21. 
Nufita, Isti, And Dhyah Setyorini. 2017. "Faktor-Faktor Yang Mempengaruhi Audit Report Lag : Studi Kasus Di Indonesia." 4: 1-20.

Sari, Indah Permata, R. Adri Setiawan, And Elfi Ilham. 2014. "Faculty Of Economics Riau University ,.” Jom Fekom 1: 1-15.

Setiawan, Liswan, And Fitriany Fitriany. 2011. "Pengaruh Workload Dan Spesialisasi Auditor Terhadap Kualitas Audit Dengan Kualitas Komite Audit Sebagai Variabel Pemoderasi.” Jurnal Akuntansi Dan Keuangan Indonesia 8(1): 36-53.

Siregar, Sylvia Veronica, Fitriany Fitriany, Arie Wibowo, And Viska Anggraita. 2011. "Rotasi Dan Kualitas Audit: Evaluasi Atas Kebijakan Menteri Keuangan Kmk No. 423/Kmk.6/2002 Tentang Jasa Akuntan Publik.” Jurnal Akuntansi Dan Keuangan Indonesia 8(1): 1-20.

Ikatan Akuntan Indonesia,2018

Wendy, Isieny, Vonni Rizal, And Hnatono Hantono. 2019. "Faktor Yang Mempengaruhi Capital Structure Pada Sektor Industri Dasar Dan Kimia.” Berkala Akuntansi Dan Keuangan Indonesia, 24(1): 94. 